\title{
Development of mechanical engineering curricula at the University of Minho
}

\author{
J. C. FERNANDES TEIXEIRA, J. FERREIRA DA SILVA and P. FLORES* \\ Mechanical Engineering Department, University of Minho, Guimarães, Portugal
}

(Received 27 November 2006; in final form 12 March 2007)

\begin{abstract}
The implementation of the Bologna protocol in the European Union has set new goals for the whole higher education system as: (a) a quality assessment for university courses; (b) a framework for the exchange of students and academics; and (c) an opportunity for changing the teaching/learning procedures and methodologies. Within the context, the mechanical engineering curricula at the University of Minho have been comprehensively formulated in order to meet these and future challenges and expectations. The whole process has been based upon various cornerstones: the legal framework for the higher education system; the introduction of new learning methodologies and an accurate survey and understanding of the existing strong and week points of the previous experience. For this purpose, a comprehensive evaluation has been carried out with former students and a detailed map has been formulated regarding their professional careers and experiences. Furthermore, a discussion has been carried out in order to define the mission of the graduate in mechanical engineering. In brief, such mission may be referred by his ability to participate in the wealth creation through technology based innovation. Within this context, the curriculum has been structured in order to meet such goals. In addition to strong foundations in physics and mathematics, new subjects are introduced into the curriculum. The whole education is based upon project development which stimulates the students' initiative, responsibility and their ability to integrate knowledge. Throughout the curriculum, students are enrolled into research projects developed in the department and it is expected that a few selected projects may be taken into a quasi industrial stage.
\end{abstract}

Keywords: Mechanical engineering education; Bologna declaration

\section{Introduction}

High levels of education have been identified as prime factors necessary for sustained development. This desideratum is essential for the improvement of life conditions and safety of the Portuguese society, which should approach those of other European Union (EU) countries. The EU has defined goals that intend to ensure that the European space becomes more competitive and improve the capability of economic and social development. Innovation and knowledge were identified as the supporting pillars for this process and the driving force for its implementation (Akay 2003, De Graaff 2004). The University, as a centre for knowledge

\footnotetext{
*Corresponding author. Email: pflores@dem.uminho.pt
} 
creation and for promoting the knowledge chain, assumes a central role in the implementation of those objectives (UNESCO 2000).

The Portuguese system of science and technology is in a convergent path with the average of the EU, although still lagging behind. As an example, for the year 2001, the number of researchers per thousand of active population in Portugal was 3.4, as opposed to 5.3 in the EU (CRUP 2005). Nevertheless, over the last years a positive trend is observed owing to aggressive scholarship programmes promoted by the Portuguese Foundation for Science and Technology, which allowed the growth in the number of graduates and researchers in the scientific and technological fields.

In a rapidly evolving society a big change in the demand of engineering skills is naturally expected. Any restructuring of an engineering curriculum must take into account the correlation between society, engineering competencies and the changing paradigm of engineering education (Vinther and Sorensen 2001). The globalization and the development of information society play a crucial role in the thought on the 'Engineers of Tomorrow'. Globalization challenges engineering students from all over the world to prepare themselves for work in a culturally diverse environment where they will encounter others who define and solve problems in a different way. The future engineer must be able to work in international project groups with multidisciplinary and cross-cultural participation. During their studies the students must be given the opportunity to apply their acquired skills, to develop a deeper insight into technical subjects and to integrate them through work (Schachterle and Vinter 1996, Anderson and Hansen 2000, Helle et al. 2006).

Traditionally, solving engineering design problems is one of the basic competencies of the engineering professional activity. Moreover, they shall also be trained to tackle projects by teamwork. Meanwhile it is found that disciplines outside the science and engineering field are becoming essential for the engineering interdisciplinary knowledge. Social sciences, humanities, cultural and management studies are also as important as the traditional applied sciences for the portfolio of engineering competencies. In fact, today's engineer must be able to communicate efficiently, to work in multidisciplinary teams, to solve problems, to have an innovative and entrepreneur spirit, as well as must be aware of its own cultural, social and economical framing. In order to adapt to this new reality the engineering education must face the challenge of a changing paradigm. This is based on several principles: the promotion of a creative and innovative approach; the multidisciplinary learning environment; the use of the new information and communication technologies; the self-learning models; the Life Long Learning promotion (Heitmann 2005, Teixeira et al. 2006).

The main objective of the current work is to present and discuss the development on the mechanical engineering (ME) curricula under the framework of Bologna protocol. It focuses on the process of changing traditional Portuguese engineering curricula into new programs that meet future expectations from the both the students and the society, and at the same time fulfill the requirements of the European harmonization.

\section{The Bologna protocol: genesis and aims}

The Bologna process has its roots in 1992 when the Treaty of Maastricht was signed. This treaty, the basis of the EU, stressed the need for the free movement of capital, goods, services, and people among EU member states. Article 127 highlights the role education is to play in achieving unity. It states that 'The (European) Community shall contribute to the development of quality education by encouraging cooperation between Member States and, if necessary, by supporting and supplementing their action'. Partnerships were achieved primarily by restructuring higher 
education projects with the purpose of increasing student mobility among nations. The Bologna Declaration, issued in 1999 to create a framework for a homogeneous degree structure, builds upon several other EU initiatives: the Lisbon Convention (1997), the Sorbonne Declaration (1998), the Salamanca Conference (2001), the Prague Conference (2001), and, most notably, the 1987 ERASMUS mobility policy (European Community Action Scheme for the Mobility of University Students), which so far has had the most significant and far-reaching implications for European higher education (Langan 2002, Hedberg 2003).

The ERASMUS/SOCRATES policy played a significant role in internationalizing higher education to broaden student participation. It called for European universities to articulate their plans for internationalization in the European Policy Statement (EPS) which is submitted every 3 years to the European Commission in order to secure program funding. Generally speaking, the EPS outlines institutional support for exchange programs, shared curriculum, etc. and makes institutions to articulate their European and International activities in a more focused and strategic way. All of the EU educational schemes are based upon the principles of mobility, compatibility and transferable credits. However the Bologna Declaration, signed by $32 \mathrm{EU}$ member and non-member countries, goes considerably further in its demands to 'create a European space for Education' (Bologna Declaration 1999). It asserts that, by the year 2010, higher education institutions will have adapted a common framework of readable and comparable degrees, introduced two main study cycles in graduate and post graduate levels, constructed compatible credit systems, encouraged mobility of students and professors, promoted a European dimension in quality assurance and increase the international competitiveness of the European system of higher education. Echoing Winston Churchill's statement, 'We now have a common language to confuse us'. Last but not least, this process shifts the educational activity from the lecturer (teaching) into the student (learning), who becomes the focus point of the higher education system.

\section{Mechanical engineering before Bologna}

ME has been an important area of higher education at both graduate and post graduate levels. In the former, the system assumes two degrees: Licenciatura (duration, 5 years) and Bacharel (3 years). Portuguese Universities offer exclusively Licenciatura and Polytechnics do offer both. Post graduation (Masters) is an exclusive product of Universities as well as Doctorate degree.

Higher education in ME has been exclusively centred in public institutions and the offer in Portugal includes eight institutions with Licenciatura and another nine that offer both Licenciatura and Bacharel degrees. This refers to degrees in core ME and does not include others such as industrial, automotive, aeronautics, polymers which are often branches in ME.

In the University of Minho (created in 1974) the ME degree was one of the first technological degrees on offer and the first students were enrolled in the fall of 1976. Since then it has established itself as one of the leading options in the field, with good reputation in both the student and industrial communities.

Entrance is regulated at a national level and currently the enrolment is 50 students per year. Extra positions may be available to special groups, including transfers from other institutions or other engineering courses. The final count goes up to 65-70 new students each year. Admission requires grades over $50 \%$ in both mathematics and physics. The degree is assessed by both the Foundation of Portuguese Universities and by the Engineers professional body. This certifies the degree for a period of time, up to a maximum of 6 years. The ME degree at the University of Minho has been regularly certified for periods of 6 years. 
The curriculum is structured on a semester basis. The course includes an individual project in the final semester. In most cases this full time project is developed in the industry, though it can also be carried out in the University. Recently, some projects have been developed abroad through the Erasmus/Socrates exchange program. On average, six different subjects are introduced each semester and the weekly load is around 25 hours of lectures. These include theoretical and a combination of experimental and/or tutorial classes. In some subjects, projects are also part of the curricula. Other possibilities may include projects that are coordinated between two professors in areas that may complement each other. In the 4th $/ 5$ th years two subjects are fully dedicated to mechanical project. This is understood in the broadest sense and may include projects in energy, materials, design, automation and manufacturing, among others.

On a very brief analysis, some trends can be identified. On one hand, young graduates are very well accepted by the industry and are In demand. The number of offers from the industry for training positions often exceeds the number of students/graduates. On average, they perform at a very good level, are often drafted as employees and some have reached into high positions in companies. They proved to be adaptable in a wide variety of environments. In addition, the existence of a final project, often in the industry, has strengthened the collaboration between the industry and the University, through research projects and technical advice. However, there is difficulty in motivating young students into engineering curricula, ME included. This problem is compounded by the decline in fertility rates and subsequent reduction in the number of students leaving high school, a problem that afflicts most of the western Europe. There is little social awareness to the profession and the demands on physics and mathematics skills often creates a high attrition rate in candidates. Above-average job prospects do not appear to be highly motivating. It is not clear to authors if the high percentage (94.4) of employability in ME is or not an important factor for motivating the student for ME course.

\section{Guidelines}

ME is one of the oldest and most traditional disciplines in engineering education whose roots can be traced back to Christopher Polhem (1661-1751). The traditional program was appropriate during the 20th-century when the society transferred from an agricultural to an industrial economy. In the 21 st-century the focus is on a global market, where a holistic view on services, products and processes is central.

In structuring the ME degree, three major factors have been taken into consideration. The most obvious includes the legal directives issued by the government. A second factor results from the clear identification of the skills a $\mathrm{ME}$ is expected to have in the forthcoming future. In other words, what role will he play in the society. Finally, the previous experience in providing ME to the market for over a quarter of a century is of great relevance.

The implementation of the Bologna guidelines in Portugal has been under discussion at various levels. Some, on an informal basis, led by professional groups, Universities, Polytechnics trying in most cases to present the best scenario according to the interests of their constituencies. In addition, the government has also requested independent task groups to elaborate scenarios concerning the definition and duration of the various degrees in the higher education system. Such spread of initiatives has brought clouds of uncertainty to the implementation of the Bologna protocol. The whole process has been further confused by linking any restructuring to the funding level of the higher education system, possibly restricting the state funding to specific degrees. It should be stated that a more active role and clear decisions 
by the political leadership would have been welcome. Such guidance should have reduced the number of iterations and would focus the Universities in doing what they are expected to do: planning and implementing higher education projects. Such attitude is in stark contrast with that followed by other countries, taking Sweden as an example (Renewing Engineering Education in Sweden 1996). The proposals that were finally put into law in 2005 identified three levels: 1st level, bachelor degree (minimum 3 years); 2nd level, masters (up to 2 years) and a 3rd level, doctorate ( 3 additional years). It is also accepted that levels 1 and 2 may be merged into a single diploma (Integrated Masters - IM) in cases where there is evidence that a 5 year period of higher education is essential to develop a professional activity. IM requires a dissertation with a duration of no less than one full-time semester. Medicine and architecture have been clearly identified in this group but the option is also open to other fields. The capacity to offer 2nd and 3rd levels in the higher education system has also been based on the proven ability of any University/department in R\&D. Such an assessment is based upon the track record concerning the number of Masters and Doctorate theses and research projects/publications.

In the last few years there was growing concern that education in Universities, ME included, was increasingly becoming out of touch with the expectations. Because teaching/learning methods were essentially those practiced for many years, important skills were not being developed in young engineers. Courses were often labelled as too theoretical and not responding to the industry needs. The model was not problem based or project oriented, suffering the typical problems of such classic approach: students having a very passive participation in their own learning processes; students learning many theoretical subjects with no clear application feeling; the study not meeting the industry requirements.

An important factor is the structure of the industrial tissue. Although this should not be the single deciding factor, it must be taken into account. The University of Minho is located in a traditionally industrial area consisting of around 42000 companies, with a large share of micro or small enterprises, mostly on the secondary and tertiary sectors. The total number of workers exceeds 180000 . The most important activity sectors are the industry (40\%), trade $(30 \%)$ and services $(16 \%)$. In terms of industry the most important sectors are the textile and clothing (more than 50\%) and the manufacturing (less than 20\%).

This industrial reality was quite relevant for the restructuring of ME curricula because it still is where a large percentage of young graduates find their jobs. However, one should not be limited to this view because the industry pattern is changing with high tech industries in non traditional fields. It means that an engineering course has to be developed not only having in mind the needs of the existing industry but also to bring to the forefront the University role in promoting the development and competitiveness of a region based on innovation opportunities.

This shifting of opportunities is only part of a wider scenario in which job competition is extended beyond national borders. If this makes competition harder at home, it also opens opportunities to compete in a wider labour market.

In the following, some aspects based on the feedback obtained from the Mechanical Engineers graduated from the University of Minho during the past decade are presented. It discusses the ways in which students learn at Engineering Education and it analyses their implications for redesigning initial training and rethinking the teachers' role. Data were gathered through interviews and questionnaires. In total 161 former students participated in the study. A questionnaire was designed including both closed and open-ended questions. Four levels of information were included: biographic data (gender, age, initial training, current job position, etc.), academic education (reasons for choosing ME, reasons for selecting University of Minho, expectations about ME course, etc), transition from University to labour market (difficulties, type of work and company, etc) and graduate and post-graduate interest (areas, 


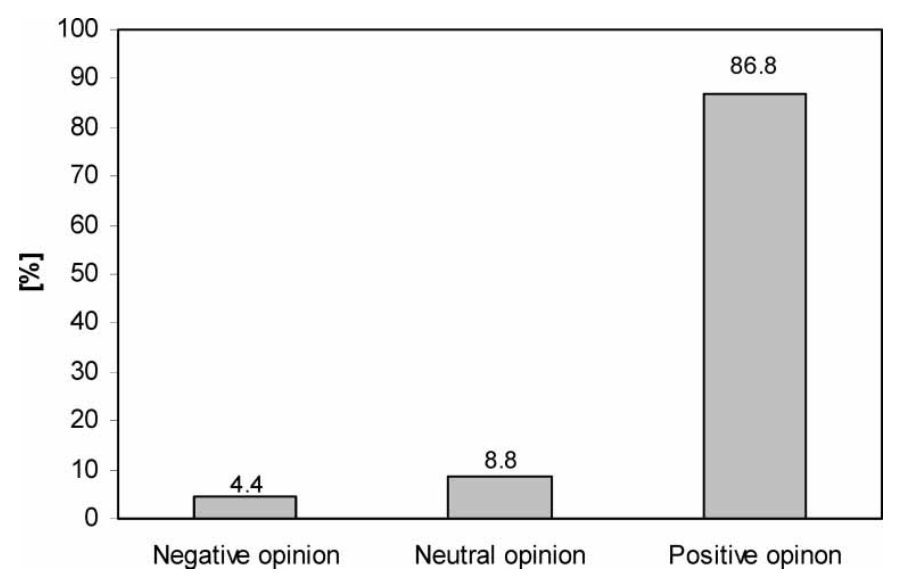

Figure 1. Balance of the quality of ME obtained from mechanical engineers from the University of Minho.

type and organization for high level courses, specific courses, Masters and $\mathrm{PhD}$ degrees). Background characteristics, such as years of experience, academic years of experience at the current job were also included. The data is statistically analyzed with the use of commercial software SPSS 11.5 ${ }^{\circledR}$ (Ferreira 2006, Flores 2006).

Findings suggest a positive evaluation of the initial training: the way students adapted to University, relationship between students, length of their practicum. They also highlight a number of issues to be improved: a more hands-on approach, a better pedagogical intervention from lecturers, a more adequate integration between secondary school and university curricula.

Figures 1 through 4 show some important results and opinions from ME relative to the topics included into the questionnaire.

From this study it was observed that the market opportunities for mechanical engineering are quite broad, from technical positions to management jobs. The mechanical engineers graduated from University of Minho over the past decade work on a wide range of companies and fields. In general the transition from University to world market was simple and successful as the graduates develop their jobs on a very satisfactory level.

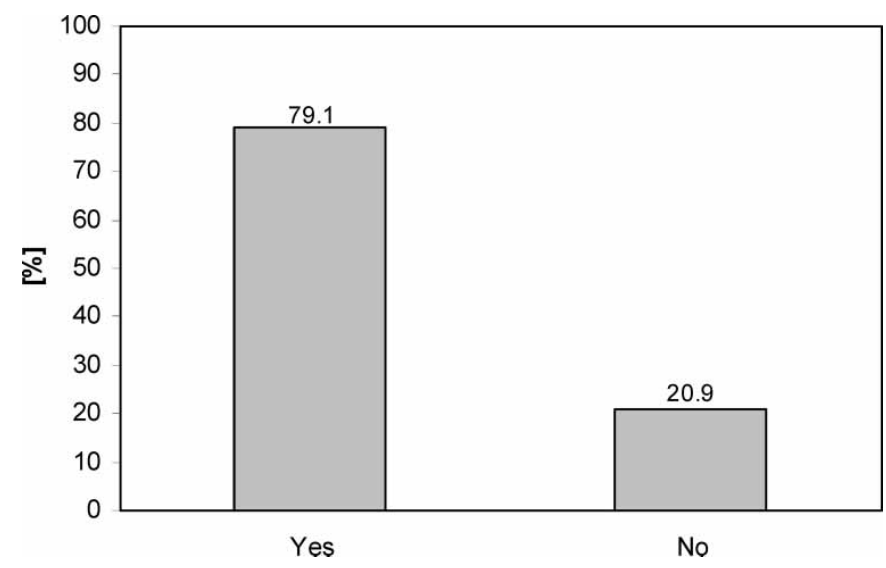

Figure 2. Answer to the question: Does the ME course correspond to the initial expectations? 


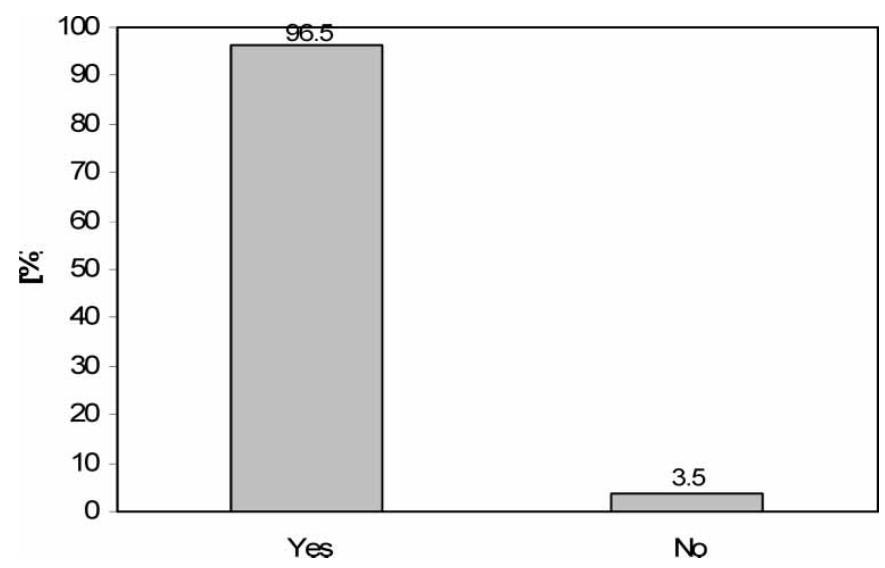

Figure 3. Answer to the question: Do the mechanical engineers work in the desired area?

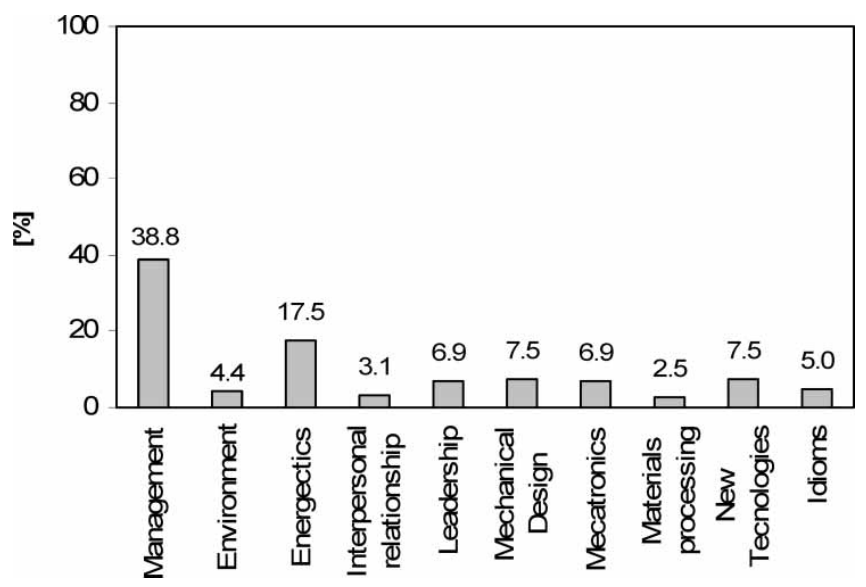

Figure 4. First priority for thematic areas of interest in post-graduate courses, such as short and long courses.

\section{Curricula development}

This exercise was viewed as an opportunity and challenge to improve the learning in ME. It followed a thorough and live discussion inside the Department. In designing the structure and contents of the ME curricula, one has to factor all the major parameters that may lead to the most appropriate formulation. The work presented here concerns the formulation of a curricula understood to better fit the foreseeable needs for the engineering professional.

The starting point was to decide which of the acceptable formats for higher education should be assumed. The prime mission of the Department is to educate professionals in ME, able to have a direct contribution in the economy and society. It must be an activity geared to product development, innovation and wealth creation. Therefore, the learning should be based on project development in order to develop the necessary skills required to improve technical knowledge and to apply and integrate such knowledge into a product. Therefore, it is a learning curve that includes solid foundations in basic and engineering sciences and applied technologies and should be part of a continuous practice through the entire curricula. Such requirements would suggest an integrated approach to the curricula, making it difficult to conceive a course made up of two distinct parts. In addition, it is also common practice in the EU that the engineering profession (charted professionals) should be practiced by graduates with 
at least ten semesters of higher education. Because an increasing number activities expected to be performed by the mechanical engineering require a charted professional, the position issued by the engineering body is a compelling argument. Combining these factors, the option for an IM is the obvious route: a 5 year course leading to the masters degree. No intermediate diploma would be issued before that period. This option is compatible with the ME Department practice in providing post graduate training at both masters and $\mathrm{PhD}$ levels.

It is expected that the ME will play an important role in industry, in technological developments and in society. In addition to the skills that have been taken for granted (technical expertise) and that should be broadened and developed, those in economics and management are added. It is expected that the ME should have a wider contribution in the society: social and environmental awareness, being a leading element in wealth creation. In this context, new topics should be included in the curricula and, most importantly, the learning method should be re-engineered (Akay 2002).

It must be stated that the role that has been expected from the engineer has changed over the time. In the not so distant past, the young graduate was expected to join a company and be part of a larger organization. An increasing number of graduates are becoming entrepreneurs and this trend is expected to grow. It is the mission of the University to anticipate this trend and to provide the conditions to develop such skills.

In brief, the mission of the ME has been defined into three major aspects:

(a) to be an active member in product design and development;

(b) to be a leading element in wealth creation through technological-based entrepreneurship;

(c) to promote competitiveness through scientific innovation.

In addition, and to face the present forces of global markets and international competition, other skills should be developed: ability to work in a team; integrate the results of scientific knowledge; assess the impact of its activities upon the society and environment; be able to learn throughout life; to be resourceful and adaptable; to develop leadership and initiative; to be critical of results; able to communicate to a broad audience.

The question is how to translate such objectives into a curriculum. In this scenario, the basic structure of the curricula has been based upon the following principles. Table 1 details the proposed curriculum, on a semester by semester basis.

1. Reduction of the number of hours of lectures to a level of $15 \mathrm{~h} /$ week. This will shift the learning into the student, by increasing the time dedicated to self learning activities. This provides the basis for a broader objective that is motivation for a life-long learning activity. In addition, it brings the professor to the position of a partner in the learning process.

2. Introduction of integrated projects which are the central core of the curriculum. In every semester the students are engaged in a team project that integrates knowledge and stimulates their self-learning. The projects should develop their skills in decision making, leadership, communication, knowledge integration, planning, reporting.

3. In order to integrate the results of $R \& D$, the project developed in the 7 th semester is based in ongoing R\&D projects in the Department. This practice will help the students in developing their critical analysis, accuracy, and contact with state of the art techniques and will make them familiar with the research activities in the Department. This, in turn, will help to establish bridges between the University and the industry, once the graduates engage in a professional activity. Such outcome will help in fulfilling the broader objective of making the University an active partner in the society and helping in developing the Research activities in the University.

4. The 8th semester project is based upon the industrial and business implementation of a selected technical project. This will develop their awareness for the business side of 
Table 1. Detailed curriculum of the ME degree.

\begin{tabular}{|c|c|c|}
\hline Y. & $1 \mathrm{~S}$ & $2 \mathrm{~S}$ \\
\hline 1 & $\begin{array}{l}\text { Calculus } \\
\text { Linear algebra } \\
\text { Electromagnetism } \\
\text { Design and graphical methods } \\
\text { Materials science and technology } \\
\text { Integrated project I }\end{array}$ & $\begin{array}{l}\text { Calculus } \\
\text { Mechanical metallurgy } \\
\text { Computer programming } \\
\text { CAD } \\
\text { Mechanics } \\
\text { Integrated project II }\end{array}$ \\
\hline 2 & $\begin{array}{l}\text { Calculus } \\
\text { Electronics } \\
\text { Mechanics of materials I } \\
\text { Statistics } \\
\text { Thermodynamics } \\
\text { Integrated project III }\end{array}$ & $\begin{array}{l}\text { Mechanics of materials II } \\
\text { Automation and control I } \\
\text { Numerical methods } \\
\text { Fluid mechanics } \\
\text { Manufacturing I } \\
\text { Integrated project IV }\end{array}$ \\
\hline 3 & $\begin{array}{l}\text { Automation and control II } \\
\text { Machine design I } \\
\text { Heat tansfer } \\
\text { Manufacturing II } \\
\text { CAM/CAE } \\
\text { Integrated project V }\end{array}$ & $\begin{array}{l}\text { Mechanical design } \\
\text { Machine design II } \\
\text { Tribology } \\
\text { Industrial energetics } \\
\text { Computational mechanics } \\
\text { Integrated project VI }\end{array}$ \\
\hline 4 & $\begin{array}{l}\text { Process control } \\
\text { Economics analysis } \\
\text { Heat treatment } \\
\text { Heat and fluid engines } \\
\text { Specialization I } \\
\text { Integrated project VII }\end{array}$ & $\begin{array}{l}\text { Specialization II } \\
\text { Advanced physics } \\
\text { Production management } \\
\text { Integrated project VIII }\end{array}$ \\
\hline 5 & $\begin{array}{l}\text { Specialization III } \\
\text { Thesis }\end{array}$ & $\begin{array}{l}\text { Industrial management } \\
\text { Thesis }\end{array}$ \\
\hline
\end{tabular}

engineering, improve their ability in risk taking, cost analysis, financing. This project will be partnered with a non profit organization (TecMinho) that is specialized in capital risk management, intellectual property protection, spin offs. In addition, the students are brought into contact with topics in industrial and economic engineering.

5. Projects are assessed in terms of their scientific and technical merit and also by the quality of presentations, reporting, and dissemination. English will be mandatory in such activities.

6. The specialization is introduced into the curricula by modules in specific areas. Such fields should reflect those areas in which the Department has a stronger role: materials/manufacturing; energy and environment; design and structures. This approach provides good flexibility in arranging the most appropriate subjects at a given time.

7. Short conferences, speeches by invited participants will complement their training.

8. The final year is mostly dedicated to the development of the project thesis. The details framing the thesis in terms of scientific assessment, objectives, duration have been worked out as a set of rules. Its main objective is to guarantee an adequate scientific level of the dissertation. The project is to be carried out in the University, although it may be developed (and it is desired) in coordination with an industrial partner.

The coordination of such programmes (both at the semester level and also to integrate the learning trajectory for each class) requires an extensive work of planning and coordination by the Department. In addition, the professors are expected to adapt their procedures to the new orientations in the sense that they must be active participants in the student's learning process. They must be partners and, as such, be involved in the decision making. This process of adaptation is currently being undertaken in coordination with the Engineering Course Council and a selected group of lecturers has undertaken specific training in order to lead students in a project oriented learning environment. 
The implementation of this higher education curriculum requires that the entire educational offer must form a coherent package. It includes other post graduate courses (MSc or short technical courses) as well as a Doctoral degree. In addition, it promotes the competition between institutions. It opens the door for different offers in any specific field because not all the Universities will be able to offer all the three levels defined for the higher education system. It may provide the basis for a competitive ranking in the University system. Last but not least, the new structure will drive the education system into a higher level of efficiency because one expects a masters level to be achieved in 5 years as opposed to 7, in the previous format.

The first students will start their studies in the 2006/07 academic year. The new programmes proved to be significantly more attractive than the former ME programmes. The work is still in progress and will be for several years to come.

\section{Concluding remarks}

In short, the Bologna protocol is an excellent and challenging opportunity to change the methodologies and create a uniform structure for graduate and post graduate courses. The aim of this master's degree is to form ME professionals with a wide spectrum of skills, in order to make them adaptable to the working market needs. The graduate in ME can tackle problems in a wide range of sectors and this is a very important asset nowadays, both in public and private sectors.

The primary, and still traditional, mission of the universities is education and research. Actually this mission has been extended into widening the interaction with society in terms of creation, protection and dissemination of scientific knowledge. In this, the university-industry consortium and the entrepreneurship play a crucial role. That's why education and research must walk together and product development, as an objective, must constitute the philosophy of a ME course.

In our point of view, the new curriculum program achieves the main goals that constitute the basis of a successful approach for a modern engineering education, namely:

(a) further integrate education and research;

(b) flexible engineering education;

(c) cooperation with industry;

(d) learning-focused;

(e) internationalization;

(f) student participation.

This transition process is not expected to be trouble free. Past experiences in Holland and Scandinavia have proved that a considerable effort must be put into the process by the academia. In brief and wise words it can be stated that this approach leaves the lecturers with tired and strained faces. But happy!

\section{Acknowledgements}

The authors would like to express their gratitude to all those who have collaborated and contributed to the discussion leading to the current curricula.

\section{References}

Akay, A., The renaissance engineer: educating engineers in a Post-9/11 World. Eur. J. Engng Edu., 2003, 28, $145-150$.

Akay, A., New directions in mechanical engineering, big-ten-plus mechanical engineering department heads, 2002 (Clearwater Beach: Florida). 
Anderson, A. and Hansen, J., The Engineering College of Copenhagen: Engineers of Tomorrow, SEFI (European Society for Engineering Education) Annual conference: New Engineering Competencies (2001), 2000.

Bologna Declaration, The European Higher Education Area, Joint Declaration of the European Ministers of Education, Bologna, 19 June 1999.

Conselho de Reitores da Universidades Portuguesas (CRUP), A Universidade Pública Portuguesa: Reflexão para uma política de desenvolvimento. Available online at www.crup.pt (accessed 10 May 2005).

De Graaff, E. and Christensen H. P., Editorial: Theme issue on the active learning in engineering education. Eur. J. Engng Edu., 2004, 29, 461-463.

Ferreira, O.M.P.N., Formação Inicial, Transição para o mundo do Trabalho e Perspectivas de Desenvolvimento Profissional, Um estudo realizado na UM com Licenciados em Engenharia Mecânica, MSc Dissertation, University of Minho, Portugal, 2006.

Flores, P., Formação em Engenharia Mecânica na Universidade do Minho: Formação Inicial, Transição para o Mundo do Trabalho e Perspectivas de Desenvolvimento Profissional. Technical report, University of Minho, 2006. Available online at www.dem.uminho.pt. (accessed 21 December 2006).

Hedberg, T., The impact of the Bologna Declaration on European engineering education. Eur. J. Engng Edu., 2003, 28, $1-6$.

Heitmann, G., Challenges of engineering education and curriculum development in the context of the Bologna process. Eur. J. Engng Edu., 2005, 30, 447-458.

Helle, L., Tynjälä, P. and Olkinuora, E., Project-based learning in post-secondary education - theory, practice and rubber slings shots. Higher Edu., 2006, 51, 287-314.

Langan, E., The European Union: ERASMUS in Paris, New York: Nova Science Publishers, 2002.

Renewing Engineering Education in Sweden, edited by I. Ingemarsson and I. Bjorck, 1996. NyIng Project Report/Department of System Technology, Institute of Technology: Linköping University, Sweden.

Schachterle, L. and Vinther, O., Introduction: the role of projects in engineering education. Eur. J. Engng Edu., 1996, 21, 115-120.

Teixeira, J.C.F., Silva, J.C.L.F. and Flores, P., Development of mechanical engineering curricula at the University of Minho. In Proceedings of ASME 2006 International Mechanical Engineering Congress and Exposition, Chicago, Illinois, USA, 5-10 November 2006, 7p.

UNESCO (United Nations Educational, Scientific and Cultural Organization) World Education Report: the Right to Education, 2000 (UNESCO: Paris).

Vinther, O. and Sorensen, P., SEFI Annual Conference, Copenhagen, September 2001.

\section{About the authors}

José Carlos Fernandes Teixeira is an Associate Professor at the Department of Mechanical Engineering, University of Minho. He holds a PhD in Chemical Engineering from the University of Birmingham, UK and has been working in both numerical and experimental techniques in fluid mechanics and heat transfer. Of particular interest are applications in energy problems. He is currently leading a Portuguese consortium in bioenergy. J. C. Teixeira served as the head of the Mechanical Engineering Department through December 2006 and in that capacity coordinated the transition process for the mechanical engineering curriculum.

Jaime Ferreira da Silva is an Associate Professor of the Mechanical Engineer Department of the University of Minho. His PhD work has been developed on mechanical engineering design and the main field of his teaching and researching activity relies on Industrial Automation. His teaching experience together with the fact that he is the director of the Continuing Education Office of the University of Minho has been the basis of the significant work developed in Curriculum definitions both on high education graduation courses and life-long learning university policies.

Paulo Flores is currently Assistant Professor at the Department of Mechanical Engineering, University of Minho. He is a mechanical engineer with research experience in the following areas: mechanical systems analysis and design, multibody dynamics, computer-aided design, impact dynamics, tribology, engineering education. One of his fields of expertise is in engineering education, namely, on Project Led Education. He has developed important work on the development of mechanical engineering curriculum, based on the opinions collected from alumni, professionals and employers, through a systematic study support by Mechanical Engineering Department. 